\title{
Fluoroquinolone-related neuropsychiatric and mitochondrial toxicity: a collaborative investigation by scientists and members of a social network
}

Kamaljeet Kaur, BS,,$^{*}$ Raja Fayad, MD, ${ }^{1,2^{*}}$ Arpit Saxena, BS,$^{*}$ Norma Frizzell, $\mathrm{PhD},{ }^{3}$ Anindya Chanda, $\mathrm{PhD},{ }^{4}$ Suvarthi Das, MS, ${ }^{4}$ Saurabh Chatterjee, PhD, ${ }^{4}$ Shweta Hegde, MS, ${ }^{1}$ Manjeshwar Shrinath Baliga, PhD, ${ }^{5}$ Venkatesh Ponemone, PhD, ${ }^{6}$ Matthew Rorro, BS, ${ }^{1}$ Jennifer Greene, BS, ${ }^{1}$ Yasmine Elraheb, BS,${ }^{1}$ Alan J Redd, PhD, John Bian, PhD, ${ }^{8}$ John Restaino, DPM, JD, MPH, ${ }^{8}$ LeAnn B Norris, PharmD, PCPS, BCOP, ${ }^{8,9}$ Zaina P Qureshi, PhD, ${ }^{8,10}$ Bryan L Love, PharmD, ${ }^{8,9}$ Brandon Bookstaver, PharmD, ${ }^{8}$ Peter Georgantopoulos, MPH, MA, ${ }^{8,9,10}$ Oliver Sartor, MD, ${ }^{11}$ Dennis W Raisch, PhD, MS, RPh, ${ }^{12}$ Gowtham Rao, MD, PhD, ${ }^{8,9}$ Kevin Lu PhD, ${ }^{8}$ Paul Ray, PhD, ${ }^{8}$ William Hrusheshky, MD,${ }^{13}$ Richard Schulz, PhD,${ }^{8}$ Richard Ablin, PhD, DSc, ${ }^{14}$ Virginia Noxon MS,${ }^{8}$ and Charles L Bennett, $\mathrm{MD}, \mathrm{PhD}, \mathrm{MPP},{ }^{8,9, \#}$ on behalf of the Southern Network on Adverse Reactions (SONAR) project

\footnotetext{
${ }^{1}$ Applied Physiology Division, Department of Exercise Science; ${ }^{2}$ Center for Colon Cancer Research; ${ }^{3}$ Department of Pharmacology, Physiology and Neuroscience, USC School of Medicine; ${ }^{4}$ Department of Environment Health Sciences, at the University of South Carolina, Columbia; ${ }^{5}$ Department of Research, Father Muller Medical College, Mangalore, Karnataka, India; ${ }^{6}$ Fortis-Totipotent RX Centre for Cellular Medicine, Delhi, India; ${ }^{7}$ Department of Anthropology, University of Kansas, Lawrence; ${ }^{8}$ Southern Network on Adverse Reactions (SONAR), South Carolina Center of Economic Excellence for Medication Safety, College of Pharmacy, University of South Carolina, Columbia; ${ }^{9}$ Dorn Research Institute, Columbia, South Carolina; ${ }^{10}$ Arnold School of Public Health, University of South Carolina, Columbia; ${ }^{11}$ Tulane University School of Medicine, New Orleans, Louisiana; ${ }^{12}$ College of Pharmacy, University of New Mexico, Albuquerque; ${ }^{13}$ Oncology Analytics Inc, Plantation, Florida; and ${ }^{14}$ Department of Pathology, University of Arizona College of Medicine, The Arizona Cancer Institute and BIO5 Institute, Tucson
}

Background The 3 fluoroquinolone $(F Q)$ antibiotics - ciprofloxacin, levofloxacin, and moxifloxacin - are commonly administered to oncology patients. Although these oral antibiotics are approved by the US Food and Drug Administration (FDA) for treatment of urinary tract infections, acute bacterial sinusitis, or bacterial infection in patients with chronic obstructive pulmonary disease, they are commonly prescribed off-label to neutropenic cancer patients for the prevention and treatment of infections associated with febrile neutropenia. New serious FQ-associated safety concerns have been identified through novel collaborations between FQtreated persons who have developed long-term neuropsychiatric (NP) toxicity, pharmacovigilance experts, and basic scientists. Objective To conduct basic science and clinical investigations of a newly identified adverse drug reaction, termed FQassociated disability.

Methods 5 groups of C57BL/6 mice receiving the antibiotic ciprofloxacin in 10-mg increments $(10 \mathrm{mg} / \mathrm{kg}-50 \mathrm{mg} / \mathrm{kg})$ and 1 group of control mice were evaluated. The Southern Network on Adverse Reactions (SONAR) and a social network of FQ-treated persons with long-term NP toxicity (the Floxed Network) conducted a web-based survey. The clinical toxicity manifestations reported by 94 respondents to the web-based survey of persons who had received 1 or more doses of an FQ prescribed for any indication (generally at FDAapproved dosages) and who subsequently experienced possible adverse drug reactions were compared with adverse event information included on the product label for levofloxacin and with FQ-associated adverse events reported to the FDA's MedWatch program.

Results Mice treated with ciprofloxacin had lower grip strengths, reduced balance, and depressive behavior compared with the controls. For the survey, 93 of 94 respondents reported FQ-associated events including anxiety, depression, insomnia, panic attacks, clouded thinking, depersonalization, suicidal thoughts, psychosis, nightmares, and impaired memory beginning within days of FQ initiation or days to months of FQ discontinuation. The FDA Adverse Event Reporting System (FAERS) included 210,705 adverse events and 2,991 fatalities for FQs. Levofloxacin and ciprofloxacin toxicities were neurologic $(30 \%$ and $26 \%$, respectively), tendon damage $(8 \%$ and $6 \%)$, and psychiatric (10\% and $2 \%)$. In 2013 , an FDA safety review reported that FQs affect mammalian topoisomerase II, especially in mitochondria. In 2013 and 2014, SONAR filed citizen petitions requesting black box revisions identifying neuropsychiatric toxicities and mitochrondrial toxicity as serious levofloxacin-associated adverse drug reactions. In 2015, FDA advisors recommended that FQ product labels be revised to include information about this newly identified disability syndrome termed "FQ-associated disability" (FQAD).

Limitations Basic science studies evaluated NP toxicity for only $1 \mathrm{FQ}$, ciprofloxacin.

Conclusion Pharmacovigilance investigators, a social network, and basic scientists can collaborate on pharmacovigilance investigations. Revised product labels describing a new serious adverse drug reaction, levofloxacin-associated long-term disability, as recommended by an FDA advisory committee, are advised.

Funding This work was funded partly by the National Cancer Institute (1R01CA165609-01A1), the American Cancer Society (IRG-13-043-01), the South Carolina SmartState Program, and an unrestricted from Doris Levkoff Meddin to the South Carolina College of Pharmacy Center for Medication Safety and Efficacy. 
$\mathrm{T}$ The fluoroquinolones (FQs) ciprofloxacin, levofloxacin, and mofloxacin are oral antibiotics often administered to cancer patients for prophylaxis and/or treatment of bacterial infections resulting from chemotherapy-associated febrile neutropenia. The US Food and Drug Administration (FDA) approvals support FQ treatment of a range of infections such as pneumonias, acute bacterial sinusitis, exacerbation of chronic bronchitis, skin infections, chronic bacterial prostatitis, urinary tract infections, acute pyelonephritis, and inhalational anthrax. ${ }^{1,2}$ Levofloxacin, ciprofloxacin, and moxifloxacin are currently the only FQs marketed in the United States. Newer FQs are more potent and active across a broader spectrum, have improved pharmacokinetic properties, and, if they receive FDA approval, are likely to be prescribed in place of levofloxacin, ciprofloxacin, or moxifloxacin to cancer patients for prevention or treatment of bacterial infections. ${ }^{3}$

FQs are associated with a range of toxicities. As is the case with many other medications administered to cancer patients, some FQ toxicities have not been fully characterized even though they have been in use since 1987, when ciprofloxacin ${ }^{4}$ was approved for use in the United States. Three FDA-approved FQs, temarfloxacin, trovofloxacin, gatifloxacin, were withdrawn from the market in 1992, 1999, and 2006, respectively, after the FDA received spontaneous reports of severe toxicities, including hepatotoxicity. ${ }^{2,3} \mathrm{FQ}$ product labels currently include black box warnings for tendinitis, tendon rupture, and neurotoxicity (among myasthenia gravis patients). ${ }^{1,5}$

An important part of pharmacovigilance is to understand the mechanisms of toxic effects. Preclinical models can facilitate these assessments. Previous preclinical studies identified FQ-associated abnormalities in the peripheral and central nervous systems. For example, in mice, sparfloxacin plays a role in hampering neuromuscular strength and inducing depressive behaviors after the administration of 25 $\mathrm{mg} / \mathrm{kg}$ and $50 \mathrm{mg} / \mathrm{kg}$ of the drug. ${ }^{6}$ Anxiogenic effects were also seen in mice that were administered gatifloxacin. ${ }^{7}$ Only one animal study has evaluated FQ-associated neuropsychiatric (NP) toxicity using therapeutic dosages of ciprofloxa- cin. ${ }^{8}$ That study, conducted in 30 rats, evaluated controls and rates that received doses of $20 \mathrm{mg} /$ $\mathrm{kg}$ or $50 \mathrm{mg} / \mathrm{kg}$ administered orally for 14 days. Evidence of ciprofloxacin-associated depression, anxiety, and abnormal locomotor activity and motor coordination at the $50-\mathrm{mg} / \mathrm{kg}$ dose was reported. Altered brain neurotransmitter levels and increased oxidative stress were identified and thought to be the possible mechanisms of ciprofloxacin-associated neurotoxicity. ${ }^{8}$

\section{SONAR and the Floxed Network}

The Southern Network on Adverse Reactions (SONAR) is an independent pharmacovigilance program funded by a National Cancer Institute R01 grant, a SmartState grant from the Education Lottery State of South Carolina, and additional pilot grants. ${ }^{4}$ The network's principal investigator was contacted by individuals who had experienced long-term NP toxicity following use of an FQ and who had developed a social network of individuals with concerns over possible FQ drug toxicity (the Floxed Network). In a novel collaboration, SONAR, basic scientists, and the Floxed Network conducted studies to evaluate FQ-associated NP toxicity. A basic science study with C57/BL6 mice evaluated FQ-associated NP toxicity concerns raised initially by the Floxed Network. Another study, led by members of the Floxed Network, developed, conducted, and analyzed a web-based survey of persons who experienced possible FQ-associated toxicity. SONAR and the Floxed Network analyzed FQ-associated long-term NP toxicity in FDA Adverse Event Reports (FAERS), the Floxed Network survey, and the product label for levofloxacin. The study received Institutional Review Board approval from the University of South Carolina.

\section{The mouse study}

Animal studies play an important role in drug safety evaluation, particularly in investigating possible dose-toxicity effects. FQ-associated NP toxicity was investigated by exposing C57BL/6 mice to increasing dosages of ciprofloxacin, the FQ that has been on the market the longest and is the fourth most commonly prescribed antibiotic overall. ${ }^{9}$ While ciprofloxaxin-associated NP toxicity has not been evaluated in experimental studies in humans,

\footnotetext{
*Authors contributed equally to manuscript and are considered first co-authors. $\ddagger$ Deceased. Accepted for publication July 31, 2015. Correspondence: Charles L Bennett, MD, PhD, MPP; bennettc@sccp.sc.edu. Disclosures: The authors have no disclosures to report. JCSO 2016;14:54-65. (2) 2016 Frontline Medical Communications. doi:10.12788/jcso.0167.
} 
we investigated whether previous findings of NP toxicity identified in rats could be replicated in mice, and if toxicity occurred primarily at higher doses of ciprofloxacin. In this study, as in the prior study of ciprofloxcanassociated neurotoxicity in rats, anxiety levels of animals were assessed using elevated plus maze testing. ${ }^{8}$ This test depends on behavioral inhibition associated with certain features (open elevated arms or closed arms, for example) of the test apparatus. ${ }^{10}$

\section{Methods}

\section{Basic science}

Six- to eight-week-old C57BL/6 mice housed in a conventional animal room were treated with ciprofloxacin in the Animal Resource Facility at the University of South Carolina. Treatment and control mice were kept under a 12:12 hour light-dark cycle in a low-stress environment $\left(22^{\circ} \mathrm{C}, 50 \%\right.$ humidity, low noise) with access to food (Purina Chow) and water ad libitum. They were randomly assigned to 5 treatment groups $(\mathrm{n}=10$ each; receiving $10,20,30,40$, and $50 \mathrm{mg} / \mathrm{kg}$ of ciprofloxacin, respectively) and 1 control group of 10 mice receiving placebo. Each group had equal numbers of males and females. Ciprofloxacin (Bayer, West Haven, CT) was prepared in solution in deionized water in $10,20,30,40$, and $50 \mathrm{mg} /$ $\mathrm{kg}$ concentrations, based on previous FQ studies. ${ }^{6}$ In all, $200 \mu \mathrm{l}$ of each of the concentration's drug solutions or PBS (control group) was administered orally daily for 10 days. (Dosages of roughly $2-35 \mathrm{mg} / \mathrm{kg}$ are administered to humans; assuming standard dosages of 250 and $1,500 \mathrm{mg}$ of ciprofloxacin daily, and human weights of $43 \mathrm{~kg}$ and $120 \mathrm{~kg}$ as examples ranging from light to heavy individuals. In humans, FDA-approved adult FQ dosages range from $250 \mathrm{mg}$ once or twice a day for a duration of 3-60 days, depending on the infection). ${ }^{5}$

Limb strength for mice in the treatment and control groups was measured using grip strength meters every second day over 10 days. Rotarod experiments for evaluation of locomotion and balance were performed every other day. We used an elevated plus maze (EPM) to measure the anxiogenic effects of ciprofloxacin, by comparing the time spent by mice in the maze's closed and open arms during 5 minutes. Locomotory behavior was analyzed by counting the total number of squares crossed by mice in 5 minutes on the EPM apparatus.

Mice in the treatment and control groups were euthanized with anesthesia (isoflurane, Vedco) and cervical dislocation method, on the 11th experimentation day. Blood was obtained from the inferior vena cava, quadriceps muscles, and brain. Sections from quadriceps muscles and brain tissues were fixed in 10\% formalin for immunohistochemistry. TUNEL (terminal deoxynucleotidyl transferase dUTP nick end labeling) assay and HMGB-1 (highmobility group binding protein-1) immunochemistry was performed on brain tissue slides to quantify apoptosis and necrosis.

Cellular oxygen consumption rates after ciprofloxacin treatment of $\mathrm{C} 2 \mathrm{C} 12$ (mouse myoblasts) and HT-22 (mouse hippocampal neurons) cell lines were quantified using the cell respirometer (Seahorse Biosciences). Cells were treated with $2.5,5.0,10$, and $15 \mu \mathrm{g} / \mathrm{ml}$ of ciprofloxacin for 48 hours.

SigmaStat software (version 4.0 Systat Software, San Jose, CA) was used to evaluate differences among experimental groups, using one-way and two-way analysis of variance (ANOVA) and Tukey post hoc tests. A $\mathrm{P}$ value of less than .05 was considered significant.

\section{Clinical studies}

Web-based survey. Cases were obtained with assistance of the Floxed Network. Respondents $(\mathrm{N}=94)$ were asked to describe the NP events they experienced and to note whether they had reported the events to the FDA. A third question asked the respondents about physician responses to reports by patients of possible FQ toxicity.

FAERS review. We submitted a Freedom of Information Act (FOIA) request for access to reports to the FDA from November 1, 1997 to July 21, 2015 for FQ-associated adverse events.

\section{Results}

\section{Basic science}

Grip strength values were highest for control mice during all days of experimentation except on day 0 and lowest for the treatment group that received the highest dose $(50 \mathrm{mg} /$ $\mathrm{kg}$ ) of ciprofloxacin (Figure 1A). Grip strength values were significantly lower for the 40 and $50 \mathrm{mg} / \mathrm{kg}$ ciprofloxacin treatment groups compared with the controls on all days of experimentation. Mice that received 30, 40, and $50 \mathrm{mg} / \mathrm{kg}$ ciprofloxacin showed significant decreases in numbers of successful rotations performed on the rotarod on all days of experimentation except day 0, compared with controls (Figure 1B). For the groups receiving 40 and $50 \mathrm{mg} / \mathrm{kg}$ ciprofloxacin, the number of successful rotations decreased significantly on day 10 compared with day 0 .

There was a significant increase in the percentage of closed arm entries on the EPM in all treatment groups compared with controls, except for the $10 \mathrm{mg} / \mathrm{kg}$ ciprofloxacin group (Figure 1C). The percentage of closed arm entries consistently increased with increasing ciprofloxacin dosage. There was significantly decreased locomotor activity on the open field apparatus among all treatment groups compared with their control counterparts on days 5 and 10 (Figure 1D). Significant decreases in locomotor and exploratory behavior alterations occurred for the 10,20,30, and $40 \mathrm{mg} / \mathrm{kg}$ ciprofloxacin groups on day 10 compared with day 5 within the same group. 


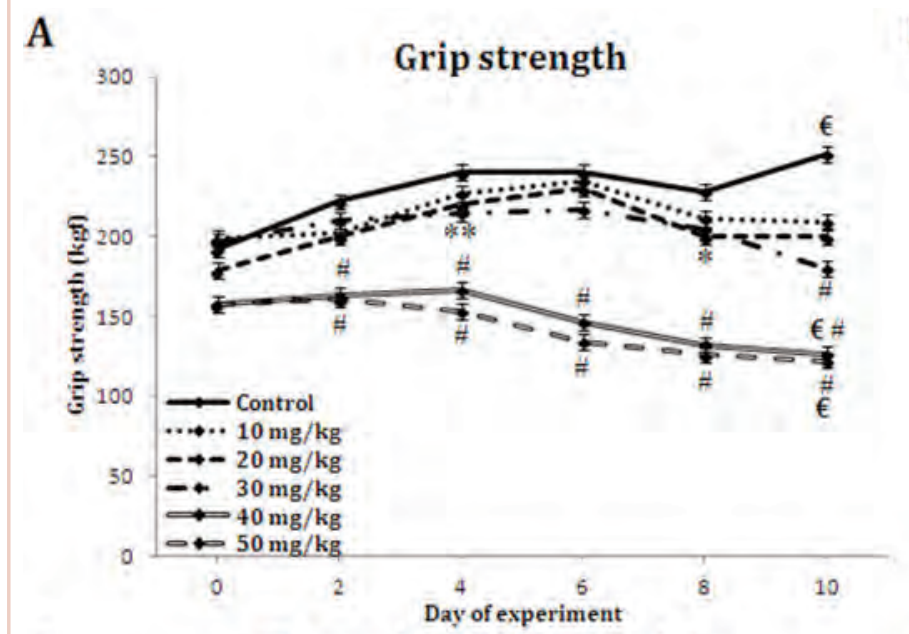

B

C

Elevated plus maze activity
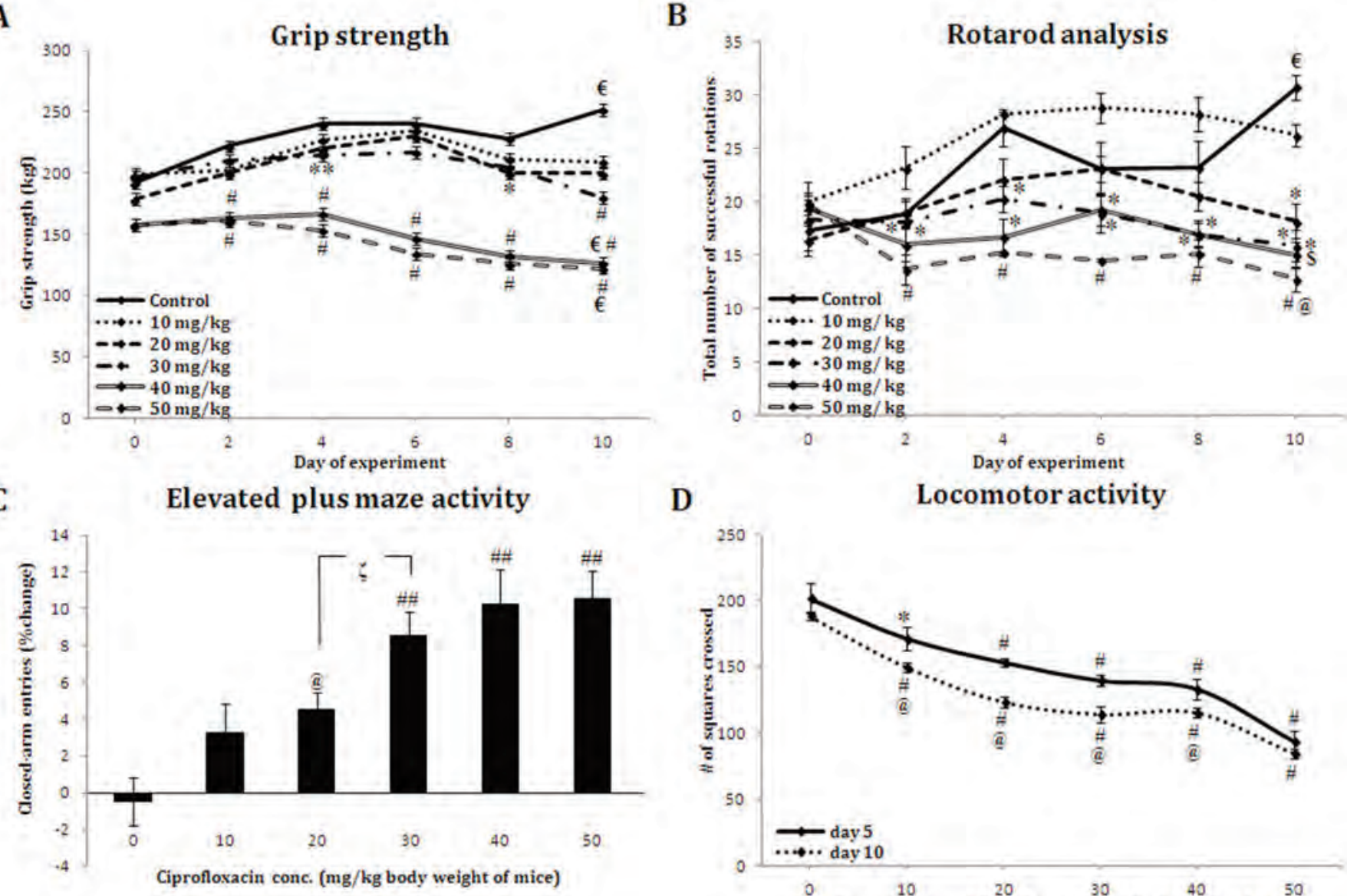

D

Locomotor activity

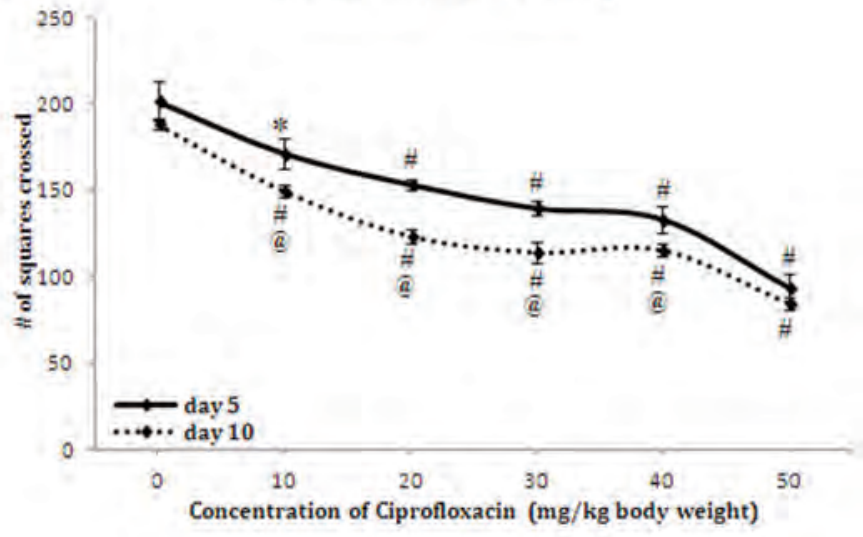

FIGURE 1 Physical and behavioral observations. Neurotoxic (A, B) and psychotoxic (C, D) effects of ciprofloxacin treatment. A, Grip strength profile of experimental mice under different dosages and controls of ciprofloxacin during the period of study. B, Changes in total number of rotations during the study for different treatment groups. C, Percentage changes in the closed arm entries from days 5-10 on the elevated plus maze for different treatment groups. D, Locomotor activity profile of mice depicted in dosage dependent manner. One-way and two-way repeated measure analysis of variance were used to calculate significant differences between: control and different ciprofloxacin treatment groups on same days of experiment, $\# P<.01,{ }^{*} P<.03,{ }^{*} P<.04$; between Day 0 and Day 10 measurements within individual ciprofloxacin treatment groups, $€ P<.01, \$ P<.05$, $@ P<.03$; and between Day 5 and Day 10 measurements within the individual ciprofloxacin treatment groups, \#\#P<.01, @P<.04, $\triangle P<.03$.

Brain cortex tissue showed significantly higher levels of apoptosis among all treatment groups compared with controls (Figure 2). Immunohistochemical studies on brain tissues revealed significantly higher expression in levels of the HMGB-1 protein among ciprofloxacin-treated mice compared with controls (Figure 3A-F and corresponded to ciprofloxacin dosage (Figure 3G).

Oxygen consumption rates for maximal respiration decreased from $1,000 \mathrm{pmoles} / \mathrm{min} / \mu \mathrm{g}$ of protein in controls, compared with $300 \mathrm{pmoles} / \mathrm{min} / \mu \mathrm{g}$ of protein in both $\mathrm{C} 2 \mathrm{C} 12$ and HT-22 cells treated with $15 \mu \mathrm{g} / \mathrm{ml}$ (highest concentration) of ciprofloxacin (figure not shown). There was a significant reduction in oxygen consumption rate for all dosages of ciprofloxacin except the $5 \mu \mathrm{g} / \mathrm{ml}$ treatment of C2C12 cells compared with controls.

\section{Clinical study}

Overall, 94 individuals responded to the Floxed Network web-based survey. Responses described a range of psychiatric effects (Table 1), including anxiety (72\%), depression (62\%), insomnia (48\%), panic attacks (37\%), cognitive impairment (33\%), depersonalization and/or derealization (29\%), suicidal thoughts (24\%), psychosis and/or hallucinations (22\%), nightmares and/or abnormal dreams (21\%), and impaired memory (21\%). About half of the survey respondents $(54 \%)$ had filed MedWatch reports with the FDA on the effects they experienced, and more than half reported that their medical providers were unaware that FQ toxicity might include the clinical events that the individual patients had reported to MedWatch (Table 2).

The psychiatric adverse events identified by Floxed 


\section{Original Report}
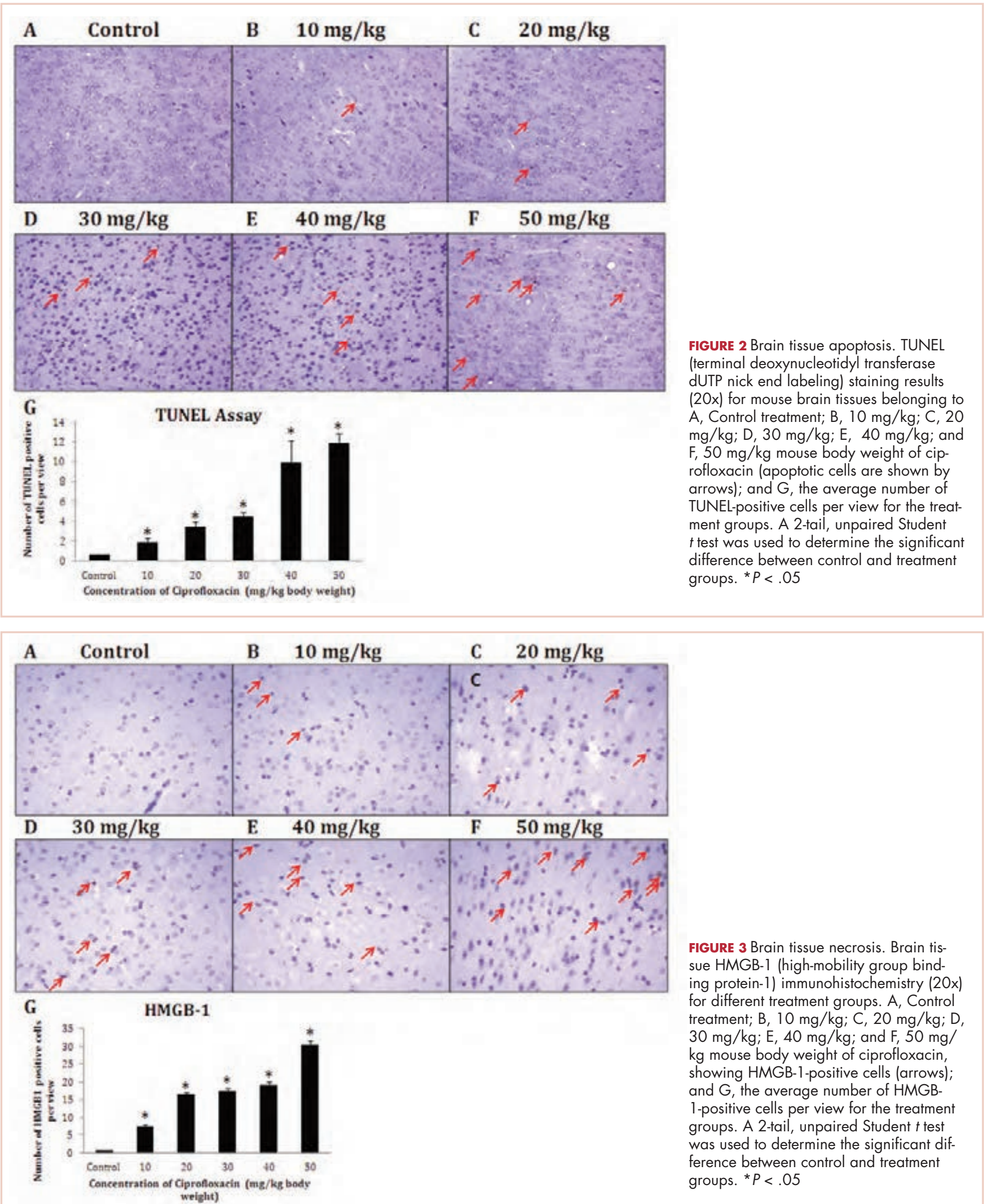

FIGURE 3 Brain tissue necrosis. Brain tissue HMGB-1 (high-mobility group binding protein-1) immunohistochemistry (20x) for different treatment groups. A, Control treatment; B, $10 \mathrm{mg} / \mathrm{kg} ; \mathrm{C}, 20 \mathrm{mg} / \mathrm{kg} ; \mathrm{D}$, $30 \mathrm{mg} / \mathrm{kg} ; \mathrm{E}, 40 \mathrm{mg} / \mathrm{kg}$; and F, $50 \mathrm{mg} /$ $\mathrm{kg}$ mouse body weight of ciprofloxacin, showing HMGB-1-positive cells (arrows); and $G$, the average number of HMGB1-positive cells per view for the treatment groups. A 2-tail, unpaired Student $t$ test was used to determine the significant difference between control and treatment groups. ${ }^{*} P<.05$ 
Network survey respondents were compared with information provided on the levofloxacin product label in 3 locations (Sections 5, 6, and 17) related to adverse events (Table 3). Several respondents reported NP toxicities that were not listed in the product label, including panic attacks (37\% of respondents); brain fog and/or cognitive impairment (33\%); depersonalization and/or derealization (29\%); impaired memory (21\%); emotional outbursts and/or mood swings (17\%); agitation (9\%); attention deficit and/or lack of concentration (9\%); sensation of pending doom (7\%); difficulty reading and/or doing math (7\%); mania and/or hyperactivity (6\%); and rage and/or temper flares (5\%).

The FDA received 210,7045 adverse event reports for marketed FQs between November 1, 1997 and July 28, 2015. For levofloxacin and ciprofloxacin, information was received for 24,777 and 22,488 patients, respectively; 98,710 and 100,865 adverse events; and 1,594 and 2,072 deaths. The most commonly reported toxicities (Figure 4) were neurologic (30\% and $26 \%)$, tendon damage ( $8 \%$ and $6 \%)$, and psychiatric (10\% and $2 \%)$.

Some levofloxacin NP adverse events reported to the FDA and included in the FAERS data are included on the levofloxacin product label, including insomnia, anxiety, depression, and confusion (Table 4). Other NP adverse events reported in FAERS are not included on the product label, including feeling abnormal, loss of consciousness, disorientation, agitation, delirium, depressed level of consciousness,

TABLE 1 Responses to the Floxed Network survey questionnaire on fluoroquinolone-associated toxicity $(N=94)$

\begin{tabular}{lc} 
Toxicity & \% reported \\
\hline Anxiety & 72 \\
\hline Depression & 62 \\
\hline Insomnia & 48 \\
\hline Panic attacks & 37 \\
\hline $\begin{array}{l}\text { Brain fog and/or cognitive } \\
\text { impairment }\end{array}$ & 33 \\
\hline $\begin{array}{l}\text { Depersonalization and/or } \\
\text { derealization }\end{array}$ & 29 \\
\hline $\begin{array}{l}\text { Thoughts of suicide } \\
\text { Psychosis and/or } \\
\text { hallucinations }\end{array}$ & 24 \\
\hline $\begin{array}{l}\text { Nightmares and/or } \\
\text { abnormal dreams }\end{array}$ & 22 \\
\hline $\begin{array}{l}\text { Impaired memory } \\
\text { Emotional outbursts (crying/ } \\
\text { giggling) and/or mood } \\
\text { swings }\end{array}$ & 21 \\
\hline $\begin{array}{l}\text { Paranoid and/or fearful } \\
\text { a }\end{array}$ & 17 \\
\hline
\end{tabular}

TABLE 2 Some responses to Floxed Network survey Question 3, What was the response from the medical community regarding your complaints?ab $(\mathrm{N}=94)$

\section{Respondent answer to the question}

Failing grade [for] the medical community. Physician behavior includes: fear, lack of curiosity, lack of reading science provided...

I was told I needed to relax.

They would actually get angry when I tried to talk to them about my symptoms. I just gave up ...

They just thought I was nuts and I was dismissed ... even though all the symptoms are listed on the pharmacy printout ... I was still dismissed.

Denial, ignorance, and zero insight - especially for the prescribing urologist.

Went into the ER and was told I just need to go on antidepressants ...

Was told I have 'magical thinking' about levofloxacin adverse events.

I feel let down by the medical community.

Said I should stop reading about the side effects of cipro ...

Medical community had no idea.

Not one doctor thought the fluoroquinolones did this to me.

They totally ignored all my problems after being given levofloxacin...

My doctors deny that these issues are connected to $F Q$ antibiotics.

Mostly disbelief - I thought I was exaggerating things.

Ignored, dismissive, dismissed, [they] seemed angry with me.

It was all in my head.

They refused to believe my problems have anything to do with taking ciprofloxacin ...

Absolutely no admission from any physician that this could possibly be caused by FQs.

'We don't think this is from antibiotics at all.'

Dismissive. Refused to acknowledge fluoroquinolone toxicity ...

Disbelief from all but one.

'We think she is depressed.'

Seemed unconcerned.

I was advised to go to counseling.

'It should be out of my system.'

a56 respondents $(60 \%)$ said they believed that the medical community was not aware of any fluoroquinolone toxicity and/or did not believe the individual's new onset medical issues could be related to a fluoroquinolone. b38 respondents $(40 \%)$ said that at least 1 physician was aware of some fluoroquinolone toxicities and/or believed the individual's new onset medical issues could be related to a fluoroquinolone. 
TABLE 3 Floxed Network survey responses on psychiatric adverse events and corresponding adverse event label information for levofloxacin

Listed in label information

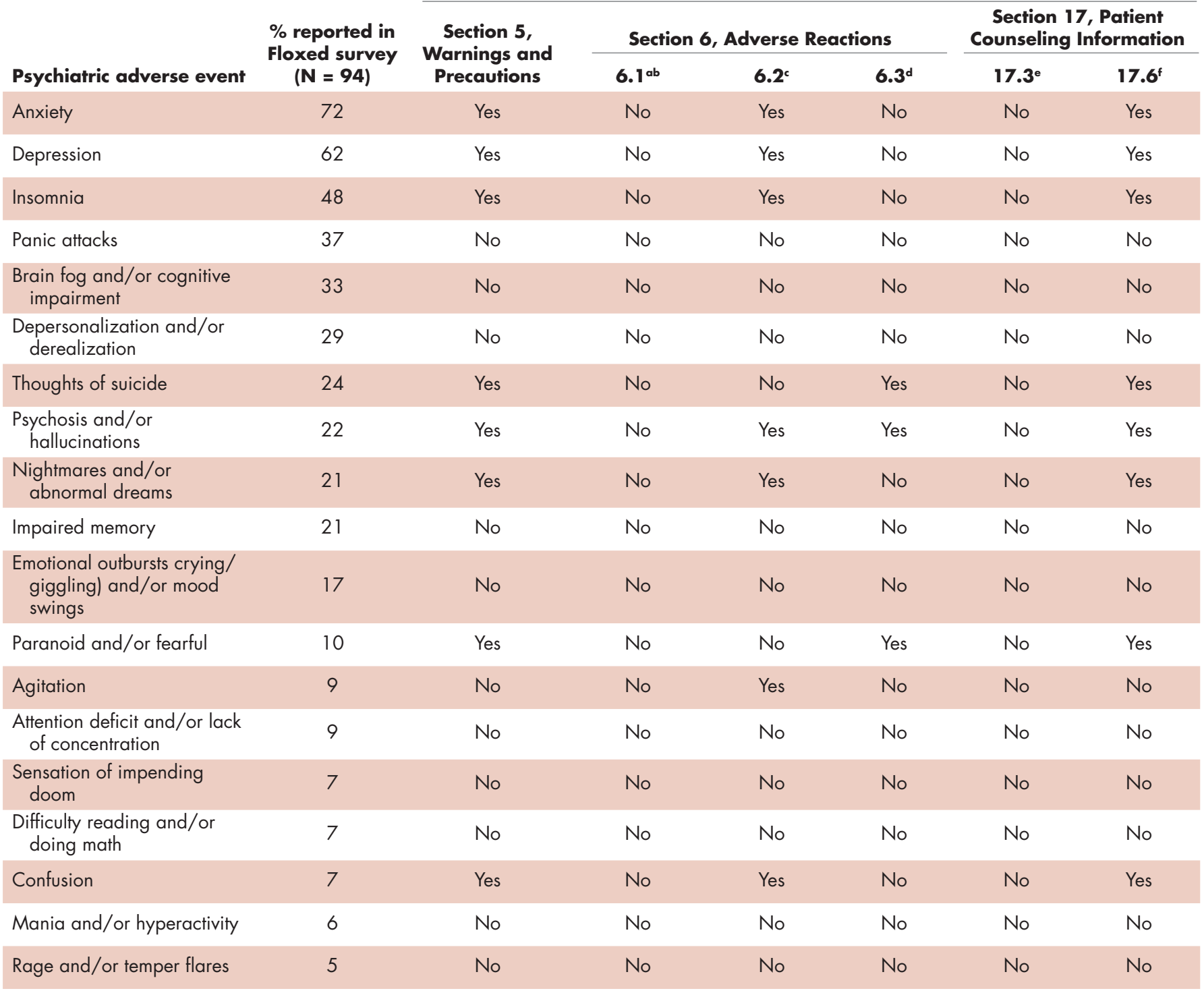

aSection 6.1 addresses Serious and Otherwise Important Adverse Reactions. bPhysicians and patients are referred to Section 5 , Warnings and Precautions. There is discussion of psychiatric adverse events under the Clinical Trial Experience and Post-marketing Experience portions of Section 6. 'Section 6.2 addresses Clinical Trial Experience. ${ }^{d}$ Section 6.3 addresses Postmarketing Experience. eSection 17.3 addresses Serious and Potentially Serious Adverse Reactions. Section 17.6 is the FDA-Approved Medication Guide.

psychotic disorder, amnesia, coma, disturbance in attention, panic attack, memory impairments, nervousness, and restlessness. In addition, according to FAERS data on levofloxacin, reports that contain descriptions of suicide ideation or suicide attempt were reported almost twice as frequently during 2006-2015, compared with 2002-2005.

Three sections on the levofloxacin product label report on adverse events: Section 5 (Warnings and Precautions); Section 6 (Adverse Reactions); and Section 17 (Patient Counseling Information). ${ }^{1}$ Reporting of psychiatric toxicities is inconsistent among the 3 sections.

In Section 5 (Warnings and Precautions), there is no subsection containing the term psychiatric. A small number of psychiatric adverse events are listed under the heading, 5.6 (Central Nervous System Effects), and include: "FQs may cause central nervous system stimulation which may lead to tremors, restlessness, anxiety, lightheadedness, confusion, hallucinations, paranoia, depression, nightmares, insomnia, and, rarely, suicidal thoughts or acts." ${ }^{[p .15]}$

In Section 6, there is no subsection containing the term psychiatric. Section 6.1 (Serious and Otherwise Important Adverse Reactions) refers to Section 5 (Warnings and Precautions). In Section 6.3 (Postmarketing Reports of Adverse Drug Reactions), "psychosis, paranoia, and iso- 


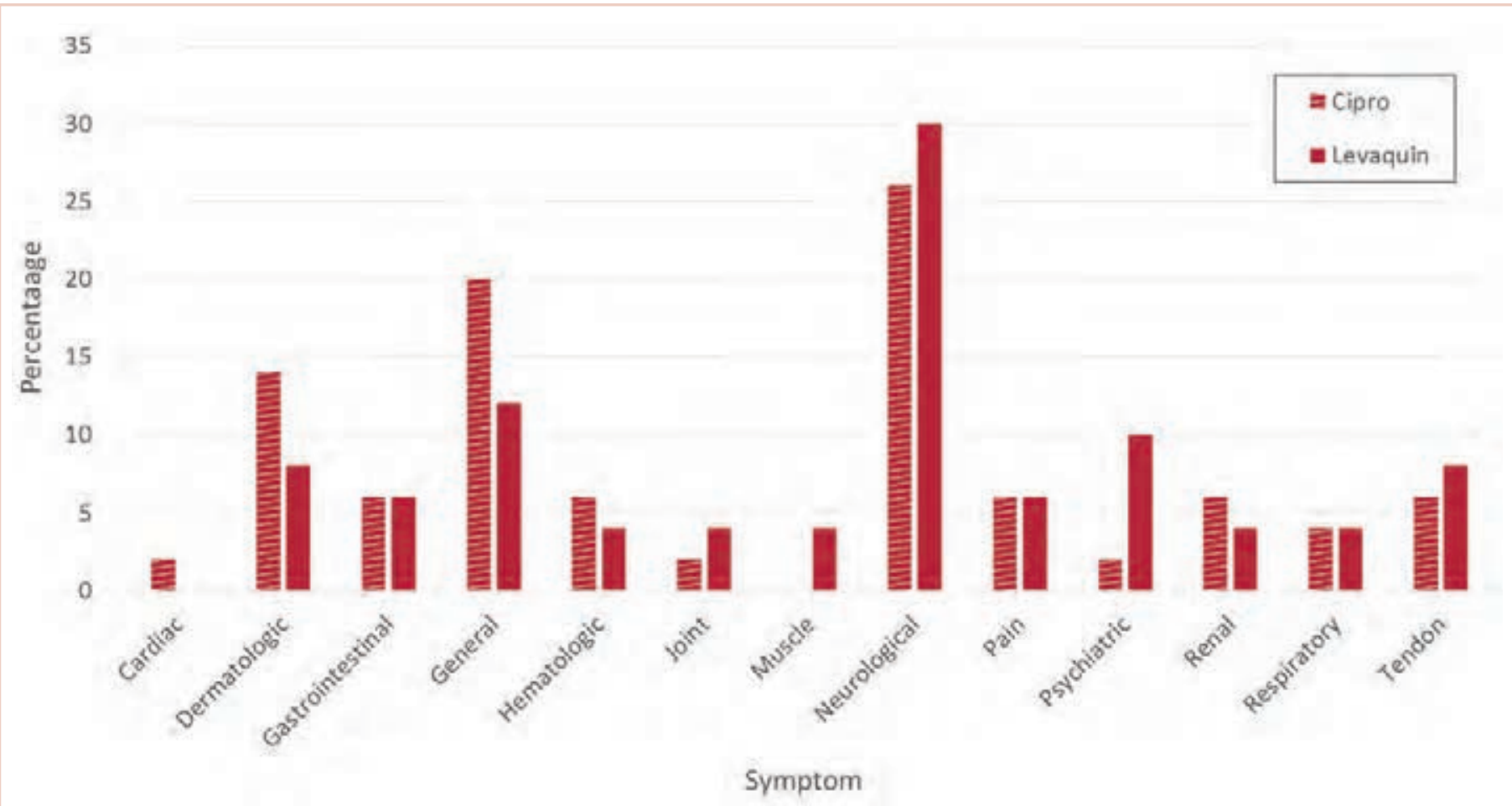

FIGURE 4 US Food and Drug Administration Adverse Event Reports data. Top 50 reported adverse events for ciprofloxacin and levofloxacin.

lated reports of suicide attempt and suicidal ideation" are listed under Psychiatric Disorders.

In Section 17 (Patient Counseling Information), there are no references to psychiatric adverse events. In Section 17.6 (Medication Guide) psychiatric adverse events are not listed under a heading that uses the term psychiatric. There are NP adverse events mixed with nonpsychiatric adverse events under the heading, Central Nervous System Effects. These include "hallucinations, restlessness, anxiety, confusion, depression, insomnia, nightmares, paranoia, and suicidal thoughts or actions". ${ }^{1[p p .66-67]}$

\section{Discussion}

This collaboration among SONAR, basic scientists, and the Floxed Network has identified FQ-associated psychiatric toxicities as toxicities that are not well described in current product labels. In interpreting our findings, several factors should be considered.

Research for evaluating potentially serious adverse drug reactions in the oncology field is limited. When an oncology patient develops toxicity, the changes are usually attributed to the cancer or chemotherapy and rarely to supportive agents or immunologic agents. Such is the case with venous thromboembolism that is associated with erythropoietin and darbepoetin, for example. ${ }^{11,12} \mathrm{With}$ respect to NP toxicity, a decade elapsed before rituximab was associated with progressive multifocal leucoencephalopathy (PML). ${ }^{13}$ More recently, PML was also identified among cancer patients being treated with brentuximab vedotin. ${ }^{14}$ These pharmacovigilance initiatives conducted by SONAR have been funded mainly by peer-reviewed grants. ${ }^{4}$ It is unlikely that similar efforts can be widely replicated because of funding limitations. SONAR is the only joint state-funded and National Cancer Institute-funded pharmacovigilance program.

Basic science studies evaluated the effects of human recommended dosages of ciprofloxacin at behavioral, cellular, and molecular levels in mouse models. Results from measurements of grip strength and balance support studies linking $\mathrm{FQs}$ to reduced physical strength and coordination in mice, $, 6,15,16$ indicating potential neurotoxicity caused by ciprofloxacin administration. Moreover, altered behavioral responses pertaining to anxiety and depression as measured by EPM and open-field experiments indicate psychotoxic potential of ciprofloxacin. ${ }^{17-20}$ The findings parallel reports of FQ-associated NP toxicity in humans. ${ }^{21-25}$

With respect to the clinical investigations, voluntary efforts from interested persons were critical. The study questions and design for the web survey were developed by the Floxed Network and reviewed and commented upon by 2 external pharmacovigilance investigators who have extensive experience with FAERS reports. The survey was designed with input from SONAR investigators and conducted and analyzed by the Floxed Network. The survey results parallel results from a 2001 survey, ${ }^{23}$ which also involved members of the Floxed Network. ${ }^{23}$ In that study, 
TABLE 4 FAERS levofloxacin data on psychiatric adverse events (November 1997-June 2012) and corresponding adverse event label information for levofloxacin

Listed in label information

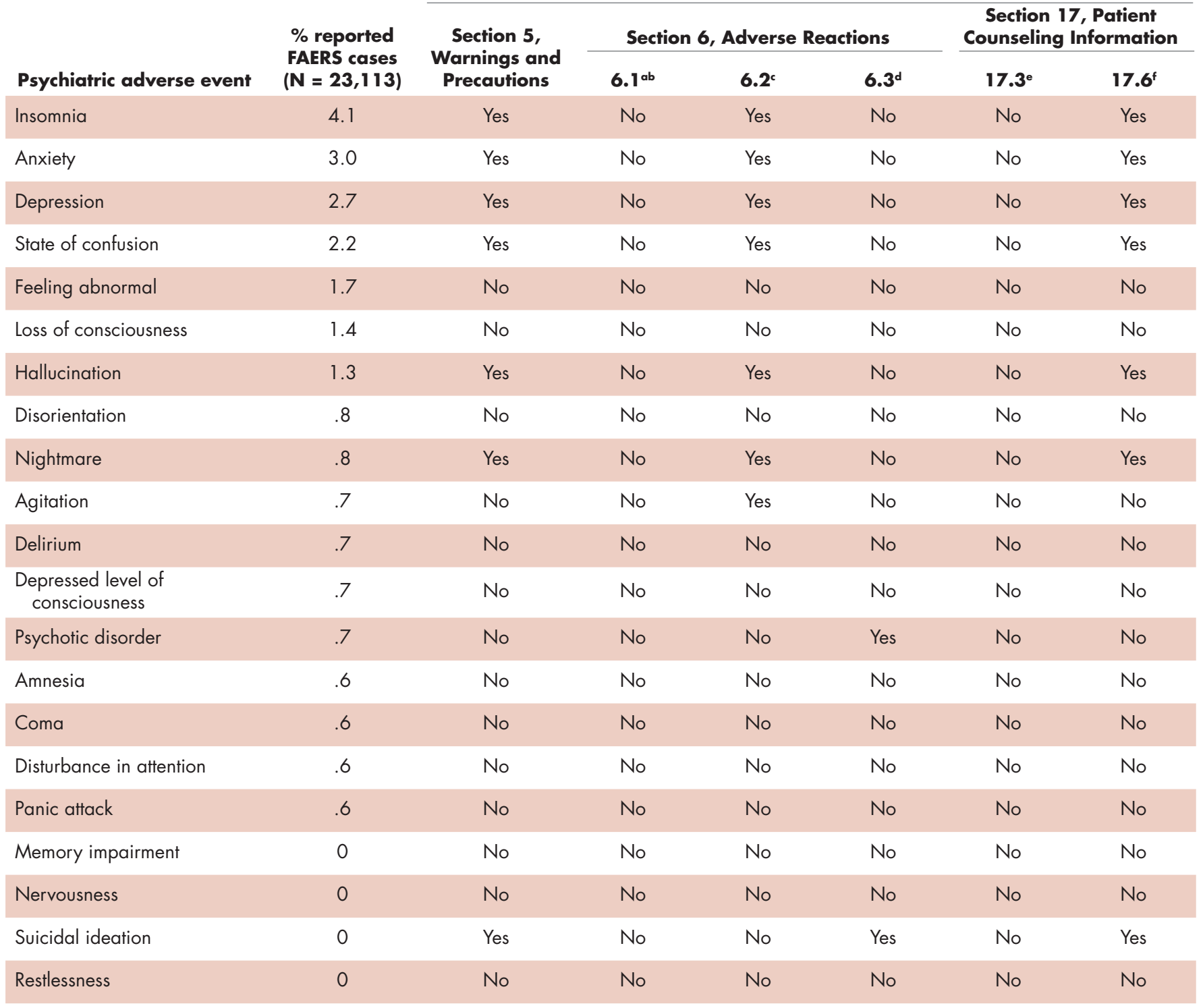

FAERS, US Food and Drug Administration's Adverse Event Reporting System

a Section 6.1 addresses Serious and Otherwise Important Adverse Reactions. bPhysicians and patients are referred to Section 5, Warnings and Precautions. There is discussion of psy-

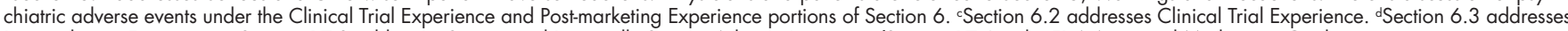
Postmarketing Experience. eSection 17.3 addresses Serious and Potentially Serious Adverse Reactions. Section 17.6 is the FDA-Approved Medication Guide.

Cohen and colleagues reported that 36 of 45 persons who had received FQs and had subsequently developed possible neuorologic toxicity had reported that the neurologic dysfunction were severe, with symptoms lasting longer than 3 months in $71 \%$ of cases and more than 1 year in $58 \%$. Onset was usually rapid, with 15 patients (33\%) reporting events that began within 24 hours of initiating treatment, 26 (58\%) within 72 hours, and 38 (84\%) within 1 week. Almost all of the patients who reported long-term neuro- logic or psychiatric toxicities in the Cohen survey and in the present survey differ from persons who typically report serious adverse drug reactions to pharmaceutical manufacturers or the FDA in that the latter group generally reports acute events such as cardiac, severe dermatologic, or pulmonary dysfunction. Overall, web sites provide opportunities for patients to report possible serious adverse drug reactions that represent potential long-term toxicities.

Our findings are in stark contrast to existing language in 


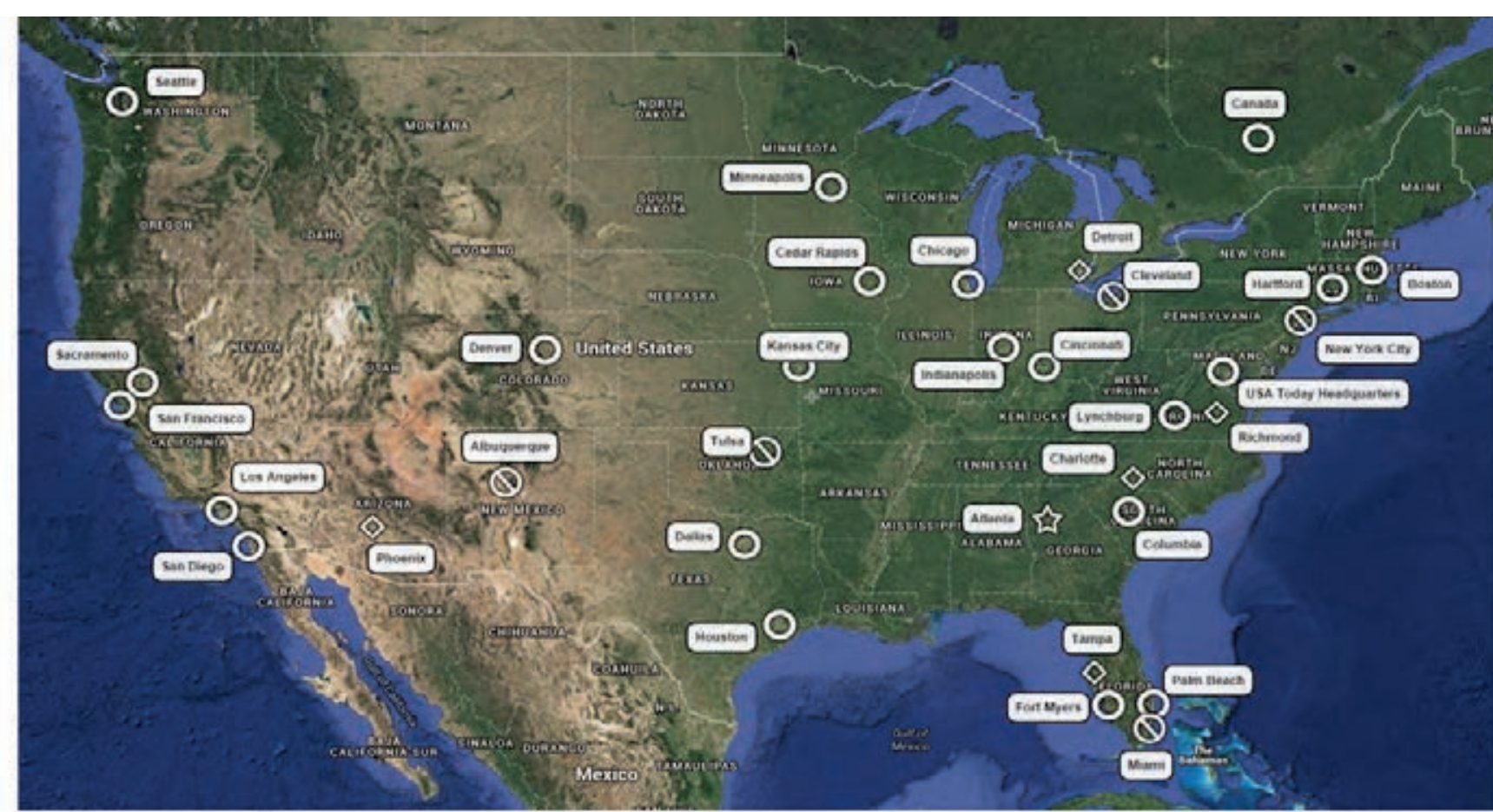

1 newscast

2 newscasts

3 newscasts

7 newscasts

FIGURE 5 Local news coverage of people with suspected adverse events from fluoroquinolone use after local news agencies were informed of the filing of citizen petitions for FQ-associated NP and mitochondrial toxicity in 2013 and 2014 (November 4, 2014 to November 6, 2015).

product labels. Although physicians and patients provide feedback on adverse events to the FDA on a regular basis, the Postmarketing Experience sections of FQ labels were updated for only 4 major toxicities during $2007-2013 .^{26,27,28}$ Three revisions, under the heading, Nervous System Disorders, describe exacerbation of myasthenia gravis, irreversible cases of peripheral neuropathy, and occurrences of pseudotumor cerebri. In 2013, based on FAERS data that identified an increasing number of reports of irreversible peripheral neuropathy, the FDA required FQ manufacturers to revise the language in the product labels' Peripheral Nervous System sections by replacing the words "rare cases" with "may be irreversible". $26,27,28$ The most significant change in FQ labels was in 2008, when a black box warning for tendon rupture and tendinitis for all $\mathrm{FQs}$ was added after a patient, with the assistance of the attorney general of Illinois, filed a citizen petition with the FDA. ${ }^{26,27,28}$ (This filing strategy was developed by SONAR, and the first successful petition was filed in 2006). ${ }^{29}$ Having access to revised product label toxicity sections has real-life implications: after the 2008 revision for FQ-associated tendon rupture, the percentages of levofloxacin-associated FAERS reports containing information on tendonitis or tendon rupture increased from $39.8 \%$ in 2008 to $72.4 \%$ in 2011.

The FQ safety initiative continues. In April 2013, a pharmacovigilance review from the Division of
Pharmacovigilance of the FDA's Office of Surveillance and Epidemiology (OSE) focused on peripheral neuropathy because of consumer communications describing prolonged, disabling, neuropathy that was thought to be associated with FQs. It was the third OSE review focusing on FQ-associated neuropathy, following 2 earlier reviews in 2001 and 2003. The review recommended that the Warnings and Precautions sections of product labels for FQs should be consistent and should indicate that irreversible neurologic toxicity may develop rapidly and be permanent, even with drug discontinuation. The review reported that FQs affect mammalian topoisomerase II, especially in mitochondria, and that that might be the underlying pathophysiology. In 2014, SONAR submitted citizen petitions to the FDA requesting that levofloxacin's black box warning section be revised to include "possible mitochondrial toxicity" and "severe neuropsychiatric toxicities" have been observed among levofloxacin-treated persons." "30,31 On December 18, 2014 and March 9, 2015, the FDA sent interim responses to SONAR, indicating that the mitochondrial toxicity and psychiatric toxicity petitions, respectively, raised complex issues requiring extensive review and analysis and final answers would be forthcoming. ${ }^{32,33} \mathrm{On}$ April 23, 2015, the FDA convened a listening session with 4 persons from the Floxed Network who reported personal experiences, rationale, and summary of concerns supporting 
SONAR's request for the addition of "possible mitochondrial toxicity" to the levofloxacin label. ${ }^{34}$ The FDA received 96 comments on the mitochondrial toxicity request.

On November 5, 2015, the FDA convened a joint meeting of its Antimicrobial Drugs Advisory Committee and Drug Safety and Risk Management Advisory Committee focusing on review of a newly identified toxicity termed by an FDA safety reviewer as "FQ-associated disability (FQAD)." ${ }^{35}$ At the meeting, an FDA safety reviewer described 178 FQAD reports, the senior author of this report described 54 persons with long-term $\mathrm{FQ}$-associated toxicity identified by SONAR, and 22 persons reported to the committee members their personal experiences with long-term toxicity following FQ use. ${ }^{36,37}$ The FDA, SONAR, and in-person cohorts were similar with respect to age (median 46 years, range 16-83 years; median 48 years, range 13-84 years; median 46 years, range 17-70 years, respectively), percentage male $(11 \%, 22 \%, 27 \%)$, onset $\leq 2$ days after FQ initiation (86\%, 92\%, 95\%), and disability of 1 month or more in all 3 cohorts. The FDA advisory committees voted for revising FQ product labels for FDA-approved indications (21-0 for the urinary tract label change, 18-2 for the sinusitis label change, and 20-0 for the chronic obstructive pulmonary disease-acute bacterial exacerbation label change). ${ }^{38}$ At the time of going to press, final responses to the citizen petitions had not been received because the FDA and FQ manufacturers were still considering actions to be taken in response to recommendations made by the advisory committees

These safety concerns were described and covered in

\section{References}

1. Levaquin [product information]. Titusville, NJ: Janssen Pharmaceuticals Inc. http://www.accessdata.fda.gov/drugsatfda docs/label/2013/020634s065,020635s071,021721s032lbl.pdf. Revised September 2013. Accessed January 1, 2016.

2. Liu HH. Safety profile of the fluoroquinolones: focus on levofloxacin. Drug Safety. 2010;33:353-369.

3. Sousa J, Alves G, Fortuna A, Falcao A. Third- and fourth-generation fluoroquinolone antibacterials: a systematic review of safety and toxicity profiles. Curr Drug Saf. 2014;9:89-105.

4. Lu ZK, Kessler SJ, Schulz R, et al. Systematic approach to pharmacovigilance beyond the limits: the Southern Network on Adverse Reactions (SONAR) Projects. Adv Pharmacoepidemiol Drug Saf. 2014;3(2). doi: 10.4172/2167-1052.1000149.

5. Ciprofloxacin [product characteristics]. Wayne, NJ: Bayer Health Care. http://www.accessdata.fda.gov/drugsatfda_docs/label/2013/0 19537s081,020780s0391bl.pdf. Revised January 2013. Accessed July 28, 2015.

6. Bharal N, Pillai KK, Vohora D. Effects of sparfloxacin on CNS functions and urinary hydroxyproline in mice. Pharmacol Res. 2006;54:111-117.

7. Bharal N, Gupta S, Khurana S, Mediratta PK, Sharma KK. Anxiogenic and proconvulsant effect of gatifloxacin in mice. Eur J Pharmacol. 2008;580:130-134.

8. Ilgin S, Can OD, Atli O, Ucel UI, Sener E, Guven I. Ciprofloxacininduced neurotoxicity: evaluation of possible underlying mechanisms. Toxicol Mech Methods. 2015;25:374-381

9. Hicks LA, Taylor Jr TH, Hunkler RJ. US outpatient antibiotic prescribing, 2010. N Engl J Med. 2013;368:1461-1462. mainstream media (Figure 5) between November 2014 (after the filings of the citizen petitions) and November 2015 (after the FDA advisory committee meeting), after the media received copies of the citizen petitions. Local television stations in 50 cities across the United States reported on the serious FQ-associated adverse drug reactions that were described in the citizen petitions. Each report included an interview with a person (or family member of a person) who had recently developed severe FQ-associated NP or in 1 instance, fatal rhabdomyolysis.

In summary, severe toxicities that develop when cancer patients receive supportive care drugs such as FQs are important, yet difficult to understand, detect, and to communicate to clinicians. Our findings support recommendations of the FDA's advisory committee that revisions of product label changes should be considered to include prominent descriptions of a newly identified FQ-associated long-term NP toxicity, termed FQ-associated disability (FQAD) by an FDA reviewer.

\section{Acknowledgments}

The authors acknowledge the Instrumentation Resource Facility at University of South Carolina School of Medicine and the Animal Resource Facility, University of South Carolina, for technical support in completion of this work. They also thank 2 anonymous international experts in pharmacovigilance for their assistance in the development of the Floxed Network survey. Raja Fayad MD, the co-first author of this manuscript, died unexpectedly following submission of this manuscript. We would like to acknowledge the assistance of Samuel Kessler and Travis Bailey during the preparation of the final revisions of this manuscript.

10. Zanoli P, Rivasi M, Zavatti M, et al. (2005). New insight in the neuropharmacological activity of Humulus lupulus L.J Ethnopharmacol 102:102-6

11. Bennett CL, Angelotta C, Yarnold PR, et al. Thalidomide- and lenalidomide-associated thromboembolism among patients with cancer. JAMA. 2006;296:2558-2560.

12. Bennett CL, Silver SM, Djulbegovic B, et al. Venous thromboembolism and mortality associated with recombinant erythropoietin and darbepoetin administration for the treatment of cancer-associated anemia. JAMA. 2008;299:914-924.

13. Carson KR, Evens AM, Richey EA, et al. Progressive multifocal leukoencephalopathy after rituximab therapy in HIV-negative patients: a report of 57 cases from the Research on Adverse Drug Events and Reports project. Blood. 2009;113:4834-4840.

14. Carson KR, Newsome SD, Kim EJ, et al. Progressive multifocal leukoencephalopathy associated with brentuximab vedotin therapy: a report of 5 cases from the Southern Network on Adverse Reactions (SONAR) project. Cancer. 2014;120:2464-2471.

15. Hamm RJ, Pike BR, O'Dell DM, Lyeth BG, Jenkins LW. The rotarod test: an evaluation of its effectiveness in assessing motor deficits following traumatic brain injury. J Neurotrauma. 1994;11:187-196.

16. Sen S, Jaiswal AK, Yanpallewar S, Acharya SB. Anxiogenic potential of ciprofloxacin and norfloxacin in rats. Singapore Med J. 2007;48:1028-1032.

17. Bale TL, Contarino A, Smith GW, et al. Mice deficient for corticotropin-releasing hormone receptor-2 display anxiety-like behaviour and are hypersensitive to stress. Nat Genet. 2000;24:410-414. 
18. Galeano P, Blanco Calvo E, Madureira de Oliveira D, et al. Longlasting effects of perinatal asphyxia on exploration, memory and incentive downshift. Int J Dev Neurosci. 2011;29:609-619.

19. Choleris E, Thomas AW, Kavaliers M, Prato FS. A detailed ethological analysis of the mouse open field test: effects of diazepam, chlordiazepoxide and an extremely low frequency pulsed magnetic field. Neurosci Biobehav Rev. 2001;25:235-260.

20. Carola V, D’Olimpio F, Brunamonti E, Mangia F, Renzi P. Evaluation of the elevated plus-maze and open-field tests for the assessment of anxiety-related behaviour in inbred mice. Behav Brain Res. 2002;134:49-57.

21. Hooper DC, Wolfson JS. The fluoroquinolones: pharmacology, clinical uses, and toxicities in humans. Antimicrob Agents Chemother. 1985;28:716-721.

22. Halkin H. Adverse effects of the fluoroquinolones. Rev Infect Dis. 1988;10(suppl 1):S258-261.

23. Cohen JS. Peripheral neuropathy associated with fluoroquinolones. Ann Pharmacother. 2001;35:1540-1547.

24. Leone R, Venegoni M, Motola D, et al. Adverse drug reactions related to the use of fluoroquinolone antimicrobials: an analysis of spontaneous reports and fluoroquinolone consumption data from three italian regions. Drug Safety. 2003;26:109-120.

25. Hall MM, Finnoff JT, Smith J. Musculoskeletal complications of fluoroquinolones: guidelines and precautions for usage in the athletic population. PM R. 2011;3:132-142.

26. FDA briefing document: joint meeting of the Antimicrobial Drugs Advisory Committee and the Drug Safety and Risk Management Advisory Committee. FDA website. http://www.fda.gov/downloads/AdvisoryCommittees/CommitteesMeetingMaterials/Drugs/ Anti-InfectiveDrugsAdvisoryCommittee/UCM467383.pdf. Dated November 5, 2015. Accessed January 17, 2016.

27. Bayer Healthcare. Briefing document for the FDA advisory committee meeting for fluoroquinolones. FDA website. http://www.fda.gov/ downloads/AdvisoryCommittees/CommitteesMeetingMaterials/ Drugs/Anti-InfectiveDrugsAdvisoryCommittee/UCM467384.pdf. Dated November 5, 2015. Accessed January 17, 2016.

28. Janssen Research \& Development LLC. Advisory committee background document: joint meeting of the Antimicrobial Drugs Advisory Committee and the Drug Safety and Risk Management Advisory Committee on fluoroquinolone safety. FDA website. http://www.fda.gov/downloads/ AdvisoryCommittees/CommitteesMeetingMaterials/Drugs/AntiInfectiveDrugsAdvisoryCommittee/UCM467387.pdf. Approved October 2, 2015. Accessed January 17, 2016.

29. Chen B, Restaino J, Norris L, et al. A tale of two citizens: a State Attorney General and a hematologist facilitate translation of research into US Food and Drug Administration actions - a SONAR report. J Oncol Pract. 2012;8:e158-167.

30. Bennett CL for SONAR. Citizen petition from Southern Network on Adverse Reactions (SONAR) [for label change to include psychiatric toxicities]. http://www.regulations. gov/\#!documentDetail;D=FDA-2014-P-1611-0001. Dated September 8, 2013; filed September 9, 2013. Accessed January 7, 2016.

31. Bennett CL, for SONAR. Citizen petition from Southern Network on Adverse Reactions (SONAR) [for label change to include 'possible FO-associated mitochondrial toxicity']. http://www.regulations. gov/\#!documentDetail;D=FDA-2014-P-0856-0001. Dated June 18, 2014; posted July 17, 2014. Accessed January 17, 2016.

32. Interim response from CDER to Southern Network on Adverse Reactions [for FQ-associated adverse toxicities]. http://www.regulations.gov/\#!documentDetail;D=FDA-2014-P-1611-0003. Dated March 9, 2015. Accessed January 17, 2016.

33. Interim response from CDER to SONAR. http://www.regulations.gov/\#!documentDetail;D=FDA-2014-P-0856-0007. Dated December 17, 2014. Accessed January 17, 2016.

34. Memorandum of meeting between FDA and Floxed Network. http://www.regulations.gov/\#!documentDetail;D=FDA2014-P-0856-0008. April 23, 2015. Accessed January 17, 2016.

35. Joint meeting of the Antimicrobial Drugs Advisory Committee (formerly known as the Anti-Infective Drugs Advisory Committee) and Drug Safety and Risk Management Advisory Committee meeting announcement. FDA website. http://www.fda.gov/ AdvisoryCommittees/Calendar/ucm465275.htm. Last updated Octoer 27, 2015. Accessed January 17, 2016.

36. Oral presentation of Debra Boxwell, Pharm D. Joint meeting of the Antimicrobial Drugs Advisory Committee and the Drug Safety and Risk Management Advisory Committee. FDA website. https://collaboration.fda.gov/p644nkzdcva/?launcher=false\&fcsContent=true \&pbMode=normal. Dated November 5, 2015. Accessed January 17, 2016.

38. Oral presentation of Charles L Bennett, MD, PhD, MPP. Joint meeting of the Antimicrobial Drugs Advisory Committee and the Drug Safety and Risk Management Advisory Committee. FDA website. https://collaboration.fda.gov/p644nkzdcva/?launcher=fals e\&fcsContent=true\&pbMode=normal. Dated November 5, 2015. Accessed January 17, 2016.

39. Burton TM. FDA panel seeks tougher antibiotic labels. http:// www.wsj.com/articles/fda-panel-seeks-tougher-antibioticlabels-1446784061. Published November 5, 2015. Accessed January $17,2016$. 